\title{
Circulating tumor cells and the metastatic process: the complexity of malignancy
}

\author{
Tania Di Raimo ${ }^{1,2}$, Elena De Santis ${ }^{3}$, Luigi Coppola ${ }^{4}$, Mario Rosario D’Andrea1, Francesco Angelini ${ }^{1,2}$ \\ 'Medical Oncology and Anatomic Pathology Unit, San Filippo Neri Hospital, Rome 00135, Italy. \\ 2Experimental \& Clinical Pharmacology, Centro Di Riferimento Oncologico - National Cancer Center, Aviano (PN) 33081, Italy. \\ ${ }^{3}$ Department of Anatomical, Histological, Legal Medical and of the Locomotor Apparatus Sciences, Sapienza University, Rome \\ 00135, Italy. \\ ${ }^{4}$ Anatomic Pathology Unit, Sandro Pertini Hospital, Rome 00157, Italy.
}

Correspondence to: Dr. Francesco Angelini, Medical Oncology and Anatomic Pathology Unit, San Filippo Neri Hospital, Via Giovanni Martinotti 20, Rome 00135, Italy. E-mail: francescoangelini01@gmail.com

\begin{abstract}
How to cite this article: Di Raimo T, De Santis E, Coppola L, D'Andrea MR, Angelini F. Circulating tumor cells and the metastatic process: the complexity of malignancy. J Cancer Metastasis Treat 2018;4:54. http://dx.doi.org/10.20517/2394-4722.2018.50
\end{abstract}

Received: 2 Aug 2018 First Decision: 31 Aug 2018 Revised: 11 Sep 2018 Accepted: 9 Oct 2018 Published: 25 Oct 2018

Science Editor: William Schiemann Copy Editor: Cai-Hong Wang Production Editor: Zhong-Yu Guo

\begin{abstract}
Despite improvements achieved in terms of early detection and therapeutic approach, metastatic breast cancer remains one of the principal worldwide causes of death. In recent years, due to the heterogeneous response of each patient to chemotherapy, clinical research highlights the need of a personalized approach. Circulating tumor cells (CTCS) represents a promising tool for this purpose. Unfortunately, even if their correlation with severity, outcome and metastatic nature of the tumor has been established, several issues, mainly concerning their characterization and isolation, need to be solved. In this review, latest knowledge on CTCs and metastatic process in breast cancer were analyzed, aiming to understand their clinical utility and validity for a prospective therapeutic scenario.
\end{abstract}

Keywords: Breast cancer, metastasis, circulating tumor cells, personalized therapy

\section{INTRODUCTION}

Breast cancer (BC) represents the second leading cause of death among women not only in Western countries but also, as proved by new evidences, in developing countries ${ }^{[1-5]}$. $\mathrm{BC}$ has been defined as a heterogeneous disease with multiple intrinsic tumor subtypes and the possibility to develop one of them is directly related to many factors, such as aging, genetics and lifestyle (obesity, lack of physical activity, sedentary behavior and frequent alcohol consumption $)^{[6-8]}$. Furthermore, each BC subtype, with distinctive histopath-

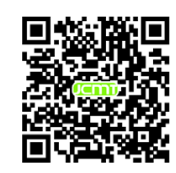


ological and biological characteristics, reflects different clinical outcomes and therapeutic strategies ${ }^{[6,9]}$. Estrogen and progesterone receptors (ER and PR) in addition to the human epidermal growth factor receptor 2 (HER-2) and the proliferation index (Ki-67) represent the most clinically used predictive biological mark$\operatorname{ers}^{[10,11]}$. Nowadays, it has been amply demonstrated how their expression is correlated with both BC intrinsic subtypes classification and the relative prognosis ${ }^{[6,12]}$. Concisely, the canonical molecular classification, firstly established by Perou in 2000, divided breast cancers in two principal subfamilies, ER- positive and ER-negative $e^{[6,12,13]}$. In the first subfamily are included the LUMINAL A $\left(\mathrm{ER}^{+} \mathrm{PR}^{+} \mathrm{HER} 2 \mathrm{Ki}{ }^{-}\right)$and LUMINAL $\mathrm{B}\left(\mathrm{ER}^{+} \mathrm{PR}^{+/} \mathrm{Her}^{+/-} \mathrm{Ki}^{+} 7^{+}\right)$subgroups that represent the most common subtypes among BC. Despite the highest incidence, luminal A has the best survival rate and is recurrence-free, while luminal B, due to their heterogeneity, presents a worse outcome together with an high risk of relapse, thus additional chemotherapy and anti-HER2 drugs treatment are needed ${ }^{[14,15]}$. The ER- subfamily includes two principal subgroups. The first subtype, called HER2 OVER-EXPRESSED (ER-PR-Her2 ${ }^{+} \mathrm{Ki} 67^{+}$), is correlated with poor prognosis and a higher risk of early relapse. Hopefully, it has been demonstrated that anti-HER2 drugs treatment brings an increment on survival and patients respond positively to chemo and neoadjuvant therapy ${ }^{[6]}$. The second ER- subgroup, the so-called BASAL LIKE, that represents $15 \%$ of BC, is characterized by an expression patterns including lack or low expression of ER, PR and HER2 in addition to a high expression of basal markers and Ki67. In the $60 \%-90 \%$ of cases, basal-like BC is TRIPLE NEGATIVE BC (TNBC), due to the absence of the principal three biological marker expressions ${ }^{[16]}$. TNBC represents a very heterogeneous subgroup comprised of further six subclasses, such as basal-like BL1 and BL2, mesenchymal-like, mesenchymal stem-like, luminal-androgen receptor expression, immunomodulatory and an unstable type subclasses ${ }^{[17]}$. In general, the TNBC subgroup exhibits, in addition to a high proliferation rate, an increase in basal/ myoepithelial cells-related cytokeratins (CKs) and epidermal growth factor receptor (EGFR) expression ${ }^{[14]}$. Furthermore, even if its heterogeneity is correlated with different prognosis and severity levels, the high percentage of TNBC patients present the worse clinical outcome, a shorter relapse-free period and a strong possibility to develop bone, lung, brain and liver metastasis ${ }^{[18,19]}$. Actually, it is clearly demonstrated that there is a strict correlation between the survival of women with BC and the incidence of distant metasta$\operatorname{ses}^{[20,21]}$. The migration of tumor cells from the primary tumor into the blood stream and their subsequent dissemination to secondary locations throughout the body represents the sine qua non condition that acts as a trigger for the entire metastatic process ${ }^{[2]}$. Nowadays, circulating tumor cells (CTCs) represent an important prognostic biomarker in early BC disease and their presence is directly correlated with the patient's response to therapy and with poor prognosis in case of recurrence in radically resected $\mathrm{BC}$ or in metastatic disease ${ }^{[23-26]}$. Nevertheless, determination and utility of CTCs, in the common clinical practice, are still object of discussion $^{[27]}$. Therefore, after a little excursion on CTCs characteristics and behavior during the metastatic process, the aim of this review is to make a point on clinical utility and validity of CTCs for a prospective therapeutic scenario.

\section{CTCs AND THEIR PLASTICITY IN THE METASTATIC PROCESS}

It is estimated that, at least in $90 \%$ of cases, metastases in distant organs represent an obstacle to the therapy and the primary cause of death in $\mathrm{BC}$ patient ${ }^{[23,28]}$. In the presence of metastatic cancers, chemotherapy is less effective on tumor cells and, as estimated by the American Cancer Society, only $22 \%$ of patients present a 5-year survival rate (www.cancer.org). Metastasis can be described as a complex dynamic multi-step process that begins with the intravasation of primary tumor-derived cells into blood or lymphatic vessels and goes on with the arrest, adhesion and extravasation of CTCs bringing to the colonization of distant organs ${ }^{[22,29,30]}$. Whenever these cells penetrate into the bone marrow, acquiring a status of dormancy, they are defined as "Disseminated Tumor Cells" (DTCs) ${ }^{[31,32]}$. Since their first detection in 1869 by Ashworth, several studies and clinical trials have demonstrated and confirmed, over the years, the strict correlation between detection and monitoring of CTCs in peripheral blood and metastatic BC (MBC), in terms of disease progression, prediction of treatment efficacy and overall-survival ${ }^{[33-43]}$. This concept has also been ratified in the eighth edition of the AJCC Cancer Staging Manual, in which circulating CTCs and bone mar- 
row DTCs detection and enumeration have been included as important prognostic tools in both Mo and M1 BC classes ${ }^{[4]}$. The ability of CTCs to perform several functional and morphologic changes, conferring them a high degree of heterogeneity and plasticity, lie behind their clinical and therapeutic attractiveness. It has been deeply highlighted the important role of epithelial to mesenchymal transition (EMT) as an essential trans-differentiation process in many physio/pathologic mechanisms, such as mesoderm formation in embryonic development, tissue repair or fibrosis ${ }^{[45-47]}$. Generally, epithelial cells are defined as adherent cells, expressing E-cadherin, a transmembrane glycoprotein involved in tight junctions' formation between adjacent cells, and CKs, such as CK8, CK18 and CK19, that exhibit an apicobasal polarity and a dense network of intercellular adhesion complexes that prevent them from migrating. In contrast, mesenchymal cells are single spindle-shaped cells that do not present intercellular junctions and, consequently, are able to migrate. In addition, mesenchymal cells generally exhibit a specific proteins profile such as vimentin, fibronectin and alpha-smooth muscle actin $(\alpha-S M A)^{[48]}$. Therefore, considering the first part of the metastatic process, in which cells loss their epithelial nature, acquire a mesenchymal-like expression profile and the detachment from the primary tumor site occurs, CTCs undergo $\mathrm{EMT}^{[49,50]}$. This multiple complex signaling system is triggered by the transforming growth factor- $\beta$ (TGF- $\beta$ ) that enhanced cell migration, invasiveness and increased ability to counteract apoptosis ${ }^{[51]}$. In fact, it has been demonstrated that TGF- $\beta$ is able to induce, in normal mammary epithelial cells, the phosphorylation of Smad2 and Smad3 and the activation of other EMT-related pathways, such as Notch, PI3K/AKT and Wnt ${ }^{[52,53]}$. This signal cascade activates EMT transcriptional factors, such as ZEB1, ZEB2, Twist, Snail and Slug, that downregulate the expression of E-cadherin ${ }^{[54-57]}$. Consequently, cell-cell adhesions are disintegrated, cytoskeleton fibers and extracellular matrix (ECM) component undergo remodeling bringing a loss of cell basal-apical polarity and a strong motile and invasive properties acquisition ${ }^{[58,59]}$. Together with E-cadherin, another epithelial-specific transmembrane protein, involved in EMT process, is the epithelial cell adhesion molecule (EpCAM). In normal conditions, this protein is localized in the intercellular space, where it is able to promote tight junctions formation and interact with E-cadherin, to maintain the epithelial integrity. On the contrary, in cancer tissue, after EMT-related cell-cell adhesion disintegration, EpCAM becomes ubiquitously distributed on the entire cancer cell surface and, for this reason, more easy to be detected with antibody-based assay. In view of this, CTCs have long been traditionally defined positive for EpCAM and CK markers expression and negative for the hematopoietic marker CD45 $\left(\mathrm{EpCAM}^{+} / \mathrm{CK}^{+} / \mathrm{CD} 45^{\circ}\right)$. However, in 2014, Lustberg et al. ${ }^{\left[{ }^{00]}\right.}$ identified different circulating cell populations in $\mathrm{MBC}$ patients composed of EpCAM/CK ${ }^{+}$cells expressing mesenchymal markers, with few or no epithelial markers, and cells with both hematopoietic and epithelial markers profile. This heterogenic nature of CTCs was also confirmed through several gene expression profiling. In fact, whilst they supported the correlation between CTCs, metastatic process and patient's overall-survival, to date no consensus has been established regarding biological markers to be used to identify these cells ${ }^{[61-63]}$. Currently, putting together different studies, among all the analyzed genes related to cell survival (IGFR1, FOXO3), the EMT process (TWIST1, SNAIL, SLUG, VIM) or tumor progression and invasion (HER2, CXCR4, uPAR, VEGFA, VEGFR, Cathepsin D) only CK19, mucin 1 (MUC1) and EpCAM result as the most accepted genes ${ }^{[6,64-68]}$. In addition, it has been demonstrated that metastasis exhibit, as primary tumors, an epithelial phenotype instead of a mesenchymal one, and that, using mice models, mammary tumors can promote an apparent EMT-independent lung metastatic process ${ }^{[69,70]}$. Considering all these evidences, an epithelial-mesenchymal plasticity (EMP) model has been proposed as a hallmark of CTCs in the metastatic process, in which circulating cells, during their migration to distant organs, are able to switch between a hybrid phenotype along the epithelial to mesenchymal spectrum conferring them the ability to adapt in different microenvironments ${ }^{[71-73]}$.

\section{CTCs migration models}

In support of the EMP model, several histopathological, intravital microscopy and in vitro studies demonstrated that CTCs exhibit different invasion strategies (collective or individual) and are able to exchange toward them according to the surrounding microenvironment ${ }^{[74-81]}$ [Figure 1]. The classical migration model 


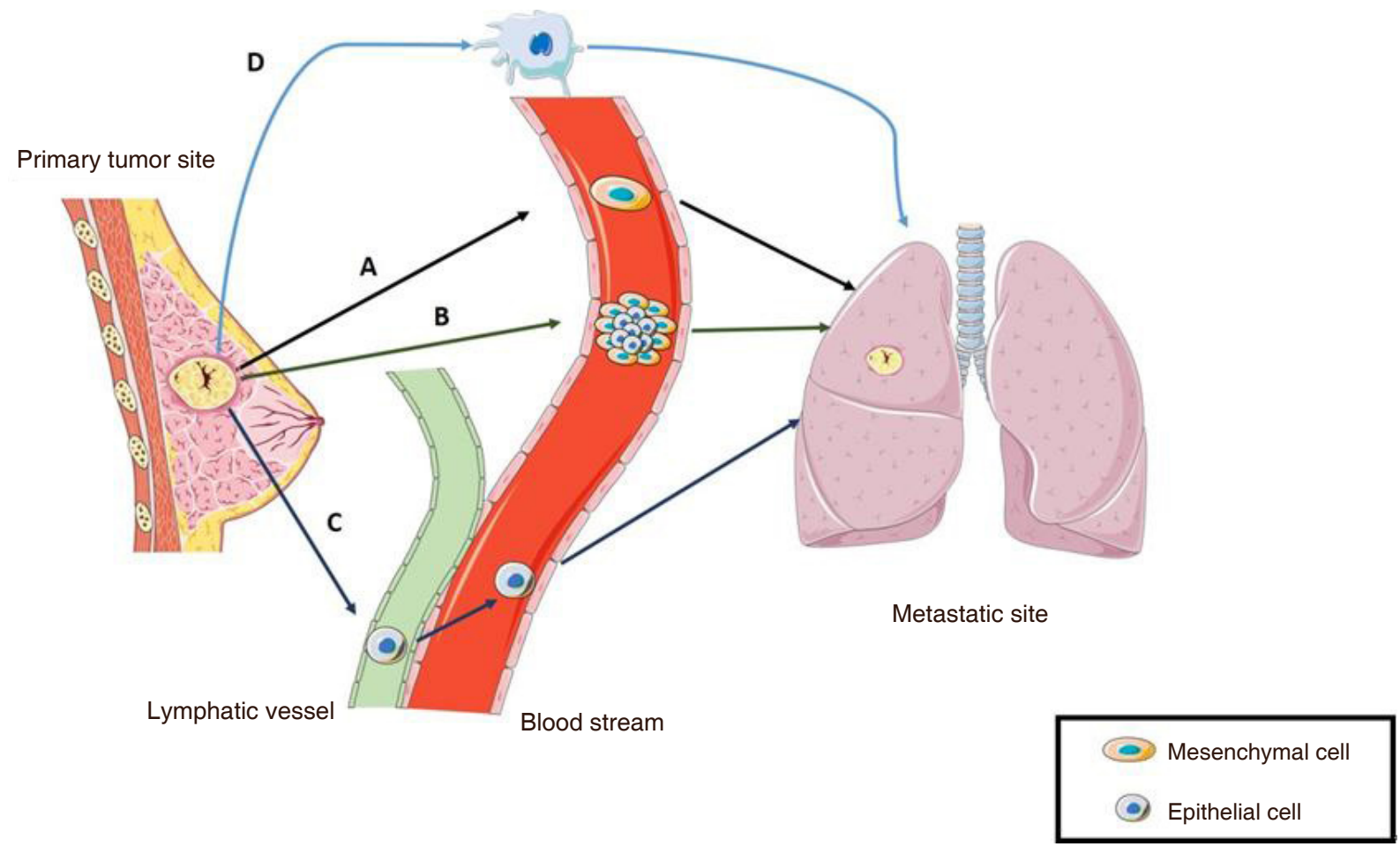

Figure 1. Cancer cells migration models. A schematic panel of tumor cells migration models discussed in the text: A: epithelial to mesenchymal transition/mesenchymal-epithelial transition process; B: collective migration model; C: lymphatic vessel pathway; D: mesenchymal to amoeboid transition process [Image created with Servier Medical Art (https://smart.servier.com/)]

depends on a reversible EMT process, known as mesenchymal to epithelial transition (MET). Primary tumor-derived CTCs, with a mesenchymal expression profile and an elongated cell shape that allows them to adhere on ECM substrate and direct their migration, are able to penetrate in the blood stream ${ }^{[82]}$. Once reached a desirable metastatic niche, CTCs promote disruption of cell adhesion and polarity, remodeling of the cytoskeleton and changes in cell-ECM adhesion ${ }^{[83,84]}$. This tissue remodeling process leads to the generation of crossing points relevant for migration and tissue invasion ${ }^{[7]}$. Subsequently, mesenchymal CTCs are able to promote MET in order to restore their epithelial profile as well as their proliferative ability. As a result, secondary tumor growth ${ }^{[78]}$ is promoted. Instead of moving through the complex EMT/MET process, another proposed mechanism suggests that epithelial and mesenchymal cells could cooperate to migrate and promote the subsequent metastatic process. In the so-called "collective migration model", it is assumed that hybrid phenotypes create and coexist in a multicellular cluster, called tumor micro-emboli or CTC cluster $^{[85]}$. By comparing both collective and individual invasion mechanisms, it is clear that the cluster migration, instead of the individual one, provides several advantages to the metastatic process ${ }^{[77,82]}$. Functionally, this structure is able to guide migration and to invade the secondary organ thanks to the mesenchymal "leader cells" that create a protective microenvironment to the poorly mobile but highly proliferate epithelial "follower" cells, inserted in the core, to accomplish the metastatic process ${ }^{[76,78,86]}$. A third mechanism, called mesenchymal to amoeboid transition, refers to a single dissociated primary tumor-derived cell that lost its attachment to the ECM adopting a distinctive spherical and highly deformable morphology with bubble-like protrusions, able to infiltrate tissues ${ }^{[77,87,88]}$. In contrast with the previous models, amoeboid migration, because it is a protease-independent process in which cells mechanically displace ECM fibrils instead of degrading them, represents at the same time a simple and efficient strategy to move through tissues and between tissue barriers ${ }^{[89,90]}$. The Met receptor tyrosine kinase (Met-RTK), a growth factor receptor, is able to promote tumor growth and metastasis by enhancing motility, survival, proliferation of cancer cells and stimulating angiogenesis ${ }^{[91]}$. In 2014, Laser-Azogui et al ${ }^{[87]}$ demonstrated that BC cells ex- 
press high levels of activated Met-RTK which are able to induce membrane blebbing and, as a consequence, cell dissociation, amoeboid motility and invasion. Furthermore, they highlighted a Met-induced protection from apoptosis and the ability of these Met-expressing cancer cells to promote the metastatic process. The lymphatic vessel pathway, due to its discontinuous structure, the high concentration of hyaluronic acid and the lymph fluid composition, which is able to improve cell survival and to reduced shear stress, represents a better and safer dissemination vehicle for cancer cells than the blood stream. Thus, it could be reasonable to consider the possibility that both epithelial and mesenchymal cancer cells migrate, preferably, through the lymphatic system, spread first to lymph nodes and then drain into the blood ${ }^{[92-94]}$. Accordingly, another mechanism of tumor EMT-independent metastasis, namely tumor-induced lymphangiogenesis, has been proposed $^{[95]}$. Briefly, mesenchymal cancer cells, which are able to produce and release lymphangiogenic factors, such as vascular endothelial growth factor C and D (VEGF-C and VEGF-D), promote an increase of lymphatic vessel density in the peri- and intratumoral area, so that epithelial cells are able to colonize lymphatic system and lymph nodes can facilitate their entry into the systemic circulation ${ }^{[96-100]}$. It has been demonstrated that an increase in lymph vessel density, due to tumor-induced lymphangiogenesis, is correlated with a high amount of lymph node metastasis, VEGF-C expression and worse disease-free/overall survival in BC patients ${ }^{[101]}$.

\section{Immune escape}

An important issue related to the EMP of CTCs and their metastatic potential is the immune-escape, which is the ability of tumor cells, during their migration, to counteract the elimination by the immune system and to increase their possibility to survive and to colonize distant organs ${ }^{[102-104]}$. One of the most studied immune evasion mechanism is the programmed death-ligand 1 (PD-L1)/programmed death receptor (PD-1) axis. In normal conditions, the PD-L1 and its PD-1 represent a physiological checkpoint of the immune system. Antigen-presenting cells express PD-L1 while PD-1 is detectable on the surface of activated T-cells. Once ligand/receptor interaction occurred, a strong inhibitory signal promotes apoptosis and functional exhaustion in T-cells ${ }^{[105]}$. In 2014, Chen et al. ${ }^{[106]}$ have identified, in lung tumor, a molecular link between the overexpression of the EMT-effector ZEB1 and a more abundant presence of PDL1, able to promote the exhaustion of intratumoral $\mathrm{T}$ lymphocytes and the development of metastasis ${ }^{[106-108]}$. Similarly, in breast cancer, it has been demonstrated that PD-L1 expression is heterogeneous and it is generally associated with the presence of poor-prognosis factors, high proliferative index and aggressive molecular subtypes ${ }^{[109,110]}$. In 2015, for the first time, Mazel et al. ${ }^{[111]}$ provided evidence that CTCs, isolated from the blood of BC patients, frequently express PD-L1 on their surface. The Fas/FasL axis represents another EMP-dependent immune escape mechanism based on the ligand/receptor interaction with a negative impact on the clinical outcome of BC patients ${ }^{[112]}$. Briefly, when the factor-associated suicide (Fas), a transmembrane receptor belonging to the tumor necrosis factor (TNF) family, interacts with its ligand (FasL), expressed on the surface of activated $\mathrm{T}$ lymphocytes, Fas-expressing cells go through apoptosis. During BC progression, Fas was found to be repressed in association with an increase of FasL level and TGF- $\beta$ secretion in tumor cells, conferring to CTCs the ability to induce cell death and escape immune recognition ${ }^{[113]}$.

\section{Metastatic niche}

Despite the migration mechanism and the above-mentioned immune evasion systems adopted by cancer cells, only a few percentage of cells that extravasate are able to survive in the unsuitable secondary organ environment and promote metastatic growth. Thus, the microenvironment in the metastatic site represents a major challenge for invading cancer cells. Starting from the "seed and soil" hypothesis, postulated by Paget, up to date, it is well known that cancer cells (the seed) require a specific and compatible "soil" microenvironment, the pre-metastatic niche, which is able to evolve and to promote both cell engraftment, creating the metastatic niche, and cell proliferation, leading to the micro- to macro- metastatic transition ${ }^{[114-119]}$. Many evidences demonstrate how primary tumor site is able to modify, before cancer cells' arrival, the secondary organ microenvironment, stimulating the creation of the pre-metastatic niche ${ }^{[120]}$. 
Tumor-secreted factors, such as VEGF-A, TNF- $\alpha$ and TGF- $\beta$, are able to promote bone marrow-derived hematopoietic progenitor cells (BMDCs) recruitment in the secondary organ. Accordingly, BMDCs recruitment results in an ECM remodeling, upregulating fibronectin (FN) and other molecules, such as MMPs, and stimulate angiogenesis ${ }^{[121]}$. Hypoxia-inducible factor (HIF) represents a major effector and adaptor in $\mathrm{BC}$ cells that, due to a massive and unregulated proliferation in association with vasculature dysfunctions, are exposed to a hypoxic microenvironment ${ }^{[122-124]}$. Lysil oxidase (LOX), one of the principal HIFdependent BC secreted factor, is strictly correlated with tumor invasiveness and lung and bone metastasis formation. In the pre-metastatic organ, LOX is able to co-localize with fibronectin and to modulate cellECM interactions ${ }^{[125]}$. Furthermore, through the interaction with type IV collagen, LOX recruits BMDCs and, in a second attempt, promotes the colonization of metastatic tumor cells ${ }^{[126-128]}$. In the matrix remodeling scenario, it has been demonstrated that the secretion of lysil oxidase-like 2 (LOX-2) is also able to induce aSMA expression in pre-metastatic fibroblasts, inducing their activation and the secretion of FN and LOX, generating a fibrotic microenvironment capable of supporting tumor cell persistence and survival ${ }^{[129,130]}$. Finally, the primary cancer secretion of VEGF, TGF- $\beta$ and TNF- $\alpha$ stimulates Angiopoietin-2 expression in the pre-metastatic niche increasing vascular permeability and, consequently, promoting the extravasation of CTCs so that metastatic process can move forward ${ }^{[131-133]}$.

\section{STATE OF THE ART IN CTCS ANALYSES}

The intrinsic mark of rarity of CTCs, in addition to their highly heterogeneous nature, represents an obstacle to study their biology ${ }^{[134,135]}$. Nevertheless, several technologies are being developed for CTCs detection in patients' peripheral blood sample based on their knowing biological properties ${ }^{[136]}$. The most commonly used techniques are based on a combination of enrichment/isolation and detection procedures. In the first phase, CTCs are separated from hematologic cells, especially leukocytes that, due to their similar physiochemical and biological properties, could contaminate tumor cell pool ${ }^{[134]}$. The enrichment procedures exploit physical (size, deformability, density and electrical charge) or biological characteristics (cell surface protein expression, viability and invasive capacity) of CTCs ${ }^{[137,138]}$. The detection step consists of immunostaining methods ranging from classic immunocytochemistry (ICC) or immunofluorescence to flow cytometry $^{[138]}$. Furthermore, RT-PCR approach represents another option to detect tumor related mRNA transcripts in patients' blood. Although this method does not require a prior CTCs enrichment, the inability to provide CTCs enumeration deeply restricts its utilisation ${ }^{[138]}$. Regarding CTCs isolation from blood components, density gradient centrifugation, such as Ficoll-Hypaque, Percoll (GEHealthcare Life sciences), OncoQuick (Greiner Bio-One), Cytotrack, Accucyte-cytefinder, represents the most commonly physical properties-based technique ${ }^{[139-141]}$. Other exploited approaches are based on cell-size separation, such as microfiltration (Screen Cell, CellSieve, ISET, Parylene filter, Filtration/Sequential ICC) or microfluidic test that combines size and deformability properties of CTCs (Ephesia, HB-CTC-chip, Iso-Flux, OncoCEE, Parsortix system, the ClearCell FX or Vortex $)^{[135,142-151]}$. Nevertheless, even if all the described isolation methods represent rapid and less expensive alternatives, they are generally hampered by blood cells-related false-positive results, thus making necessary the combination with other enrichment methods and the loss of large CTCs and CTC clusters due to the high heterogeneity of CTC size ${ }^{[136,152]}$. Immunological assays, based on the extremely specific reaction between antibodies and the target antigens on the cell surface, provide a high purity rate of isolated CTCs ${ }^{[145,153-160]}$. Several of these techniques are based on EpCAM positive selection and, actually, the most standardized method is the CellSearch ${ }^{\odot}$ system (Janssen Diagnostics), the only one approved by the U.S. Food and Drug Administration for CTCs enumeration in BC and other type of cancer ${ }^{[25,27,157,161]}$. Nevertheless, as reported by several clinical trials, in patients in which EMT occurring with the downregulation of EpCAM and other epithelial markers, this system may fail to capture the entire pool of CTCs and may result in false negative findings ${ }^{[7,134,162-165]}$. Furthermore, it has been demonstrated that the lack of EpCAM ${ }^{+}$CTCs detection does not reflect a status of benign prognosis. In fact, it could be directly related with negative hormone receptors, high tumor grade, triple-negative disease, inflammatory $\mathrm{BC}$ and brain metastasis $(\mathrm{OR}=6.17,95 \% \mathrm{CI}$ : 2.14-17.79; $P=0.001$ ) or conversely with bone 
metastasis $(\mathrm{OR}=0.47 ; 95 \% \mathrm{CI} \text { : 0.27-0.80; } P=0.01)^{[166]}$. Hence, it is important to understand, using different epithelial and/or mesenchymal markers, how defined other clinically relevant sub-populations of CTCs. Accordingly, taking into account the attested probability of false-negative results, cell-surface vimentin and EGFR were suggested as alternative markers for detecting mesenchymal transitioned CTCs ${ }^{[136,167,168]}$. To recapitulate, the common issue underlined with positive selection procedures is to fail the capture of cells with low expression of EpCAM and non-epithelial phenotypes such as those that have undergone EMT. In addition, the isolated CTCs have reduced viability and this aspect represents an important obstacle to CTCs' biological characteristics understanding ${ }^{[137]}$. Otherwise, immunological methods based on negative selection are also available. The latters are commonly used to deplete cells that do not express CD45 leucocyte antigen or a cocktail of antibodies direct against red and white blood cells, such as RosetteSep, EasySep, Dynabeads, mojoSort ${ }^{[137]}$. Cells isolated with this approach are relatively more viable but, at the same time, are highly impure. In fact, the purified cells pool contains epithelial and non-epithelial phenotypes together with normal blood vessel, stromal cells or other cells normally present in the circulation ${ }^{[137]}$. These evidences, as reported by a huge number of studies, confirm that the main challenge of CTCs isolation and characterization are the lack of specific standardized procedures that strongly restrict their use in clinical practice $^{[134,169,170]}$.

\section{CLINICAL RELEVANCE OF CTCS}

Despite progress achieved in terms of prevention, diagnosis and treatment, drug resistance and tumor relapse, whose severity and probability are specific for each patient, remain one of the principal issue in breast cancer. Therefore, as a good clinical practice, it has been established that a patient's 5 -year follow up, since primary tumor, could lead to an early detection of recurrence or metastasis and to a more specific and efficient therapy ${ }^{[169]}$. Canonical tissue biopsy represent on one side a costly, painful and hard to repeat procedure. In addition, it is not able to provide a complete genetic or epigenetic tumor characterization in order to identify possible tumor phenotypical alteration ${ }^{[171]}$. In this optic, non-invasive liquid biopsies and the measurement of specific blood-based biomarkers represent an effective alternative parameter to monitored invasive BC patients. Cancer Antigen 15-3 (CA 15-3), carcinoembryonic antigen, tissue polypeptide antigen, tissue polypeptide-specific antigen and the soluble form of HER2 represent the most detected serum BC biomarkers ${ }^{[172-174]}$. Nevertheless, even if it has been demonstrated a correlation between single or combined circulating biomarker levels and recurrence incidence, many issues need to be solved ${ }^{[175-178]}$. For instance, there are still problems associated with the lack of a validated clinically relevant level to establish, for each biomarker, a cut-off parameter ${ }^{[169]}$. Furthermore, it has been demonstrated that biomarker prognostic efficacy depends on the recurrence site. In fact, higher levels of biomarkers were detected in BC distant metastases, such as bone or liver, than in loco-regional or lung recurrence ${ }^{[179]}$. Additionally, these biomarkers are inappropriate to figure out mechanisms of therapy resistance ${ }^{[169]}$. For these reasons, nowadays, the detection of CTCs from patient blood samples appears as a powerful tool in the management of early and advanced BC patients ${ }^{[138]}$. CTC-based liquid biopsy represents a more informative tool, able to improve patients' selection and monitoring for target treatments, than conventional tumor tissue based- biomarkers that focused only on the primary tumor or metastases. Indeed, in the last few years, several studies highlighted the prognostic relevance of CTCs in MBC. In particular, it has been demonstrated that patients with a persistent CTCs count $>5$ cell per $7.5 \mathrm{~mL}$ blood had a worse patient free survival (PFS) and overall survival (OS) compared to those that have CTCs $<5$ at baseline and during follow-up ${ }^{[25,27,180-182]}$. Furthermore, due to their characteristics and minimally invasive procedures, the use of CTCs permits to evaluate the dynamic change of tumor over time for each patient that may impair the response to specific targeted treatment ${ }^{[138,183]}$. From this point of view, CTC detection appears to hold promise of a better patients' management but up to date they are not still routinely used in clinical practice. In fact, CTC enumeration and variation during treatment were independent from any other baseline clinical or pathological characteristics and were not associated with pathological complete response ${ }^{[26,27]}$. Furthermore, as highlight by the SWOG S0500 randomize trial in advanced breast cancer, there is no evidence that changing or discontinuing therapy based on CTC level could 
improve patients' health outcomes, quality of life or cost effectiveness. In addition, PFS and OS showed no difference in outcome when patients were switched to an alternate regimen ${ }^{[180]}$. Thus, the American Society of Clinical Oncology guidelines affirm that the use of CTC count alone may be prognostic but not predictive for monitoring response to treatment for metastatic breast cancer ${ }^{[184]}$. Nevertheless, several clinical trials based on the comparison in HER2/ER/PR expression profiles between patient's biopsy, from primary tumor or metastatic site, and CTCs, demonstrated a discrepancy between biopsies and circulating cells that could have important therapeutic implications ${ }^{[185]}$. In fact, it has been revealed in HER2 ${ }^{-}$and $\mathrm{ER}^{+} \mathrm{BC}$ patients the presence, respectively, of HER2 $2^{+}$and ER CTCs associated with an increased mortality risk, poor PFS and low OS ${ }^{[186-188]}$. Therefore, knowing that the switch between $\mathrm{HER}_{2}^{-/ /}$or $\mathrm{ER}^{+/-}$can occur after multiple courses in patients under HER2 targeted or ER-endocrine therapies, the monitoring of CTCs becomes crucial ${ }^{[189,190]}$. Obviously, these evidences suggest a potential mechanism of a patient's specific therapy-resistance, which is still unknown and under investigation in ongoing clinical trials ${ }^{[191]}$. In conclusion, despite several issues needing to be overcome, CTCs could be considered as a "real-time" liquid biopsy, able to provide important molecular information about patient's current disease and, hopefully, to suggest the suitable personalized treatment regimen ${ }^{[138]}$.

\section{CONCLUSION}

At present, personalized medicine represents one of the principal aims of medical research. For this reason, even the improvement achieved in treatment options and the better clinical outcomes for BC patients, conventional tissue biopsies are considered, up to date, a poor diagnostic procedure. The growing interest in CTCs and their in progress validation as diagnostic and prognostic biomarker, could represent the tool for achieving this wishes of "personalization". In fact, despite the still outstanding issues already covered in this review, CTCs could be crucial to the understanding of the complex BC heterogeneity, at the same time, they could be considered as a screening tool. Furthermore, their proved implication in the metastatic process and, most important, in chemoresistance, is stimulating the rapid development of new CTC isolation and single cell analysis platform. In the future, it is expected that the improvement in CTCs knowledge may pave the way to the discovery of new targets and to therapies that are more efficient.

\section{DECLARATIONS}

\section{Authors' contributions}

Conception and elaboration of the work: Di Raimo T, Angelini F

Provided administrative, technical, and material support: Di Raimo T, Angelini F

Revisiting the work critically for important intellectual content: Di Raimo T, D’Andrea MR, Angelini F

Final approval of the version: Di Raimo T, De Santis E, Coppola L, D’Andrea MR, Angelini F

\section{Availability of data and materials}

Not applicable.

\section{Financial support and sponsorship}

None.

\section{Conflicts of interest}

All authors declared that there are no conflicts of interest.

\section{Ethical approval and consent to participate}

Not applicable.

\section{Consent for publication}

Not applicable. 


\section{Copyright}

(c) The Author(s) 2018.

\section{REFERENCES}

1. Fitzmaurice C, Akinyemiju TF, Al Lami FH, Alam T, Alizadeh-Navaei R, et al. Global, regional, and national cancer incidence, mortality, years of life lost, years lived with disability, and disability-adjusted life-years for 29 cancer groups, 1990 to 2016: a systematic analysis for the global burden of disease study. JAMA Oncol 2018; doi: 10.1001/jamaoncol.2018.2706.

2. Al-Foheidi M, Al-Mansour MM, Ibrahim EM. Breast cancer screening: review of benefits and harms, and recommendations for developing and low-income countries. Med Oncol 2013;30:471.

3. Gyawali B, Shimokata T, Honda K, Tsukuura H, Ando Y. Should low-income countries invest in breast cancer screening? Cancer Causes Control 2016;27:1341-5.

4. Lee M, Mariapun S, Rajaram N, Teo SH, Yip CH. Performance of a subsidised mammographic screening programme in Malaysia, a middleincome Asian country. BMC Public Health 2017;17:127.

5. Rivera-Franco MM, Leon-Rodriguez E. Delays in breast cancer detection and treatment in developing countries. Breast Cancer (Auckl) 2018;12:1178223417752677.

6. Dai X, Li T, Bai Z, Yang Y, Liu X, et al. Breast cancer intrinsic subtype classification, clinical use and future trends. Am J Cancer Res 2015;5:2929-43.

7. Lammert J, Grill S, Kiechle M. Modifiable lifestyle factors: opportunities for (hereditary) breast cancer prevention - a narrative review. Breast Care (Basel) 2018;13:109-14.

8. Turkoz FP, Solak M, Petekkaya I, Keskin O, Kertmen N, et al. Association between common risk factors and molecular subtypes in breast cancer patients. Breast 2013;22:344-50.

9. Li J, Chen Z, Su K, Zeng J. Clinicopathological classification and traditional prognostic indicators of breast cancer. Int J Clin Exp Pathol 2015;8:8500-5.

10. Hammond ME. ASCO-CAP guidelines for breast predictive factor testing: an update. Appl Immunohistochem Mol Morphol 2011;19:499-500.

11. Advani PP, Crozier JA, Perez EA. HER2 testing and its predictive utility in anti-HER2 breast cancer therapy. Biomark Med 2015;9:35-49.

12. Bandyopadhyay S, Bluth MH, Ali-Fehmi R. Breast carcinoma: updates in molecular profiling 2018. Clin Lab Med 2018;38:401-20.

13. Perou CM, Sørlie T, Eisen MB, van de Rijn M, Jeffrey SS, et al. Molecular portraits of human breast tumours. Nature 2000;406:747-52.

14. Gusterson B, Eaves CJ. Basal-like breast cancers: from pathology to biology and back again. Stem Cell Reports 2018;10:1676-86.

15. Iancu G, Vasile D, Iancu RC, DaviŢoiu DV. “Triple positive” breast cancer - a novel category? Rom J Morphol Embryol 2017;58:21-6.

16. Fan C, Oh DS, Wessels L, Weigelt B, Nuyten DS, et al. Concordance among gene-expression-based predictors for breast cancer. N Engl J Med 2006;355:560-9.

17. Li Z, Qiu Y, Lu W, Jiang Y, Wang J. Immunotherapeutic interventions of triple negative breast cancer. J Transl Med 2018;16:147.

18. Jitariu AA, Cîmpean AM, Ribatti D, Raica M. Triple negative breast cancer: the kiss of death. Oncotarget 2017;8:46652-62.

19. Yousefi M, Nosrati R, Salmaninejad A, Dehghani S, Shahryari A, et al. Organ-specific metastasis of breast cancer: molecular and cellular mechanisms underlying lung metastasis. Cell Oncol (Dordr) 2018;41:123-40.

20. Wu SG, Li H, Tang LY, Sun JY, Zhang WW, et al. The effect of distant metastases sites on survival in de novo stage-IV breast cancer: a SEER database analysis. Tumour Biol 2017;39:1010428317705082.

21. Appierto V, Di Cosimo S, Reduzzi C, Pala V, Cappelletti V, et al. How to study and overcome tumor heterogeneity with circulating biomarkers: the breast cancer case. Semin Cancer Biol 2017;44:106-16.

22. Masuda T, Hayashi N, Iguchi T, Ito S, Eguchi H, et al. Clinical and biological significance of circulating tumor cells in cancer. Mol Oncol 2016;10:408-17.

23. Lianidou ES, Strati A, Markou A. Circulating tumor cells as promising novel biomarkers in solid cancers. Crit Rev Clin Lab Sci 2014;51:160-71.

24. Hiller JG, Perry NJ, Poulogiannis G, Riedel B, Sloan EK. Perioperative events influence cancer recurrence risk after surgery. Nat Rev Clin Oncol 2018;15:205-18.

25. Bidard FC, Peeters DJ, Fehm T, Nolé F, Gisbert-Criado R, et al. Clinical validity of circulating tumour cells in patients with metastatic breast cancer: a pooled analysis of individual patient data. Lancet Oncol 2014;15:406-14.

26. Bidard FC, Michiels S, Riethdorf S, Mueller V, Esserman LJ, et al. Circulating tumor cells in breast cancer patients treated by neoadjuvant chemotherapy: a meta-analysis. J Natl Cancer Inst 2018;110:560-7.

27. Cabel L, Proudhon C, Gortais H, Loirat D, Coussy F, et al. Circulating tumor cells: clinical validity and utility. Int J Clin Oncol 2017;22:421-30.

28. Tungsukruthai S, Petpiroon N, Chanvorachote P. Molecular mechanisms of breast cancer metastasis and potential anti-metastatic compounds. Anticancer Res 2018;38:2607-18.

29. Micalizzi DS, Maheswaran S, Haber DA. A conduit to metastasis: circulating tumor cell biology. Genes Dev 2017;31:1827-40.

30. Scully OJ, Bay BH, Yip G, Yu Y. Breast cancer metastasis. Cancer Genomics Proteomics 2012;9:311-20.

31. Dasgupta A, Lim AR, Ghajar CM. Circulating and disseminated tumor cells: harbingers or initiators of metastasis? Mol Oncol 2017; 11:40-61.

32. Krawczyk N, Meier-Stiegen F, Banys M, Neubauer H, Ruckhaeberle E, et al. Expression of stem cell and epithelial-mesenchymal transition markers in circulating tumor cells of breast cancer patients. Biomed Res Int 2014;2014:415721. 
33. Goodman CR, Seagle BL, Friedl TWP, Rack B, Lato K, et al. Association of circulating tumor cell status with benefit of radiotherapy and survival in early-stage breast cancer. JAMA Oncol 2018;4:e180163.

34. Giuliano M, Shaikh A, Lo HC, Arpino G, De Placido S, et al. Perspective on circulating tumor cell clusters: why it takes a village to metastasize. Cancer Res 2018;78:845-52.

35. Rossi G, Mu Z, Rademaker AW, Austin LK, Strickland KS, et al. Cell-free DNA and circulating tumor cells: comprehensive liquid biopsy analysis in advanced breast cancer. Clin Cancer Res 2018;24:560-8.

36. Wang C, Mu Z, Chervoneva I, Austin L, Ye Z, et al. Longitudinally collected CTCs and CTC-clusters and clinical outcomes of metastatic breast cancer. Breast Cancer Res Treat 2017;161:83-94.

37. Mu Z, Benali-Furet N, Uzan G, Znaty A, Ye Z, et al. Detection and characterization of circulating tumor associated cells in metastatic breast cancer. Int J Mol Sci 2016;17:E1665.

38. Dawood S, Cristofanilli M. Using circulating tumor cells to guide therapy in breast cancer: could this replace biopsies? Pharmacogenomics 2015;16:669-72.

39. Giuliano M, Giordano A, Jackson S, De Giorgi U, Mego M, et al. Circulating tumor cells as early predictors of metastatic spread in breast cancer patients with limited metastatic dissemination. Breast Cancer Res 2014;16:440.

40. Cristofanilli M. Circulating tumour cells: telling the truth about metastasis. Lancet Oncol 2014;15:365-6.

41. Jiang ZF, Cristofanilli M, Shao ZM, Tong ZS, Song EW, et al. Circulating tumor cells predict progression-free and overall survival in Chinese patients with metastatic breast cancer, HER2-positive or triple-negative (CBCSG004): a multicenter, double-blind, prospective trial. Ann Oncol 2013;24:2766-72.

42. Cristofanilli M, Fortina P. Circulating tumor DNA to monitor metastatic breast cancer. N Engl J Med 2013;369:93.

43. Dong X, Alpaugh KR, Cristofanilli M. Circulating tumor cells (CTCs) in breast cancer: a diagnostic tool for prognosis and molecular analysis. Chin J Cancer Res 2012;24:388-98.

44. Giuliano AE, Edge SB, Hortobagyi GN. Eighth Edition of the AJCC cancer staging manual: breast cancer. Ann Surg Oncol 2018;25:1783-5.

45. Stone RC, Pastar I, Ojeh N, Chen V, Liu S, et al. Epithelial-mesenchymal transition in tissue repair and fibrosis. Cell Tissue Res 2016;365:495-506.

46. Forte E, Chimenti I, Rosa P, Angelini F, Pagano F, et al. EMT/MET at the crossroad of stemness, regeneration and oncogenesis: the YingYang equilibrium recapitulated in cell spheroids. Cancers (Basel) 2017;9:E98.

47. Roche J. The Epithelial-to-mesenchymal transition in cancer. Cancers (Basel) 2018;10.

48. Kalluri R, Weinberg RA. The basics of epithelial-mesenchymal transition. J Clin Invest 2009;119:1420-8.

49. Gos M, Miłoszewska J, Przybyszewska M. Epithelial-mesenchymal transition in cancer progression. Postepy Biochem 2009;55:121-8.

50. Tiwari N, Gheldof A, Tatari M, Christofori G. EMT as the ultimate survival mechanism of cancer cells. Semin Cancer Biol 2012;22:194-207.

51. Lowes LE, Allan AL. Circulating tumor cells and implications of the epithelial-to-mesenchymal transition. Adv Clin Chem 2018;83:121-81.

52. Xu J, Lamouille S, Derynck R. TGF-beta-induced epithelial to mesenchymal transition. Cell Res 2009;19:156-72.

53. Derynck R, Muthusamy BP, Saeteurn KY. Signaling pathway cooperation in TGF- $\beta$-induced epithelial-mesenchymal transition. Curr Opin Cell Biol 2014;31:56-66.

54. Petrova YI, Schecterson L, Gumbiner BM. Roles for E-cadherin cell surface regulation in cancer. Mol Biol Cell 2016;27:3233-44.

55. Phillips S, Kuperwasser C. SLUG: critical regulator of epithelial cell identity in breast development and cancer. Cell Adh Migr 2014;8:578-87.

56. Micalizzi DS, Farabaugh SM, Ford HL. Epithelial-mesenchymal transition in cancer: parallels between normal development and tumor progression. J Mammary Gland Biol Neoplasia 2010;15:117-34.

57. Sánchez-Tilló E, Liu Y, de Barrios O, Siles L, Fanlo L, et al. EMT-activating transcription factors in cancer: beyond EMT and tumor invasiveness. Cell Mol Life Sci 2012;69:3429-56.

58. Godde NJ, Galea RC, Elsum IA, Humbert PO. Cell polarity in motion: redefining mammary tissue organization through EMT and cell polarity transitions. J Mammary Gland Biol Neoplasia 2010;15:149-68.

59. Gloushankova NA, Rubtsova SN, Zhitnyak IY. Cadherin-mediated cell-cell interactions in normal and cancer cells. Tissue Barriers 2017;5:e1356900.

60. Lustberg MB, Balasubramanian P, Miller B, Garcia-Villa A, Deighan C, et al. Heterogeneous atypical cell populations are present in blood of metastatic breast cancer patients. Breast Cancer Res 2014;16:R23.

61. Bredemeier M, Edimiris P, Mach P, Kubista M, Sjöback R, et al. Gene Expression Signatures in Circulating Tumor Cells Correlate with Response to Therapy in Metastatic Breast Cancer. Clin Chem 2017;63:1585-93.

62. Ušiaková Z, Mikulová V, Pintérová D, Brychta M, Valchář J, et al. Circulating tumor cells in patients with breast cancer: monitoring chemotherapy success. In Vivo 2014;28:605-14.

63. Yan WT, Cui X, Chen Q, Li YF, Cui YH, et al. Circulating tumor cell status monitors the treatment responses in breast cancer patients: a meta-analysis. Sci Rep 2017;7:43464.

64. Hensler M, Vančurová I, Becht E, Palata O, Strnad P, et al. Gene expression profiling of circulating tumor cells and peripheral blood mononuclear cells from breast cancer patients. Oncoimmunology 2016;5:e1102827.

65. Markiewicz A, Książkiewicz M, Wełnicka-Jaśkiewicz M, Seroczyńska B, Skokowski J, et al. Mesenchymal phenotype of CTC-enriched blood fraction and lymph node metastasis formation potential. PLoS One 2014;9:e93901.

66. Lasa A, Garcia A, Alonso C, Millet P, Cornet M, et al. Molecular detection of peripheral blood breast cancer mRNA transcripts as a surrogate biomarker for circulating tumor cells. PLoS One 2013;8:e74079.

67. Molloy TJ, Devriese LA, Helgason HH, Bosma AJ, Hauptmann M, et al. A multimarker QPCR-based platform for the detection of circulating tumour cells in patients with early-stage breast cancer. Br J Cancer 2011;104:1913-9.

68. Obermayr E, Sanchez-Cabo F, Tea MK, Singer CF, Krainer M, et al. Assessment of a six gene panel for the molecular detection of 
circulating tumor cells in the blood of female cancer patients. BMC Cancer 2010;10:666.

69. Christiansen JJ, Rajasekaran AK. Reassessing epithelial to mesenchymal transition as a prerequisite for carcinoma invasion and metastasis. Cancer Res 2006;66:8319-26.

70. Fischer KR, Durrans A, Lee S, Sheng J, Li F, et al. Epithelial-to-mesenchymal transition is not required for lung metastasis but contributes to chemoresistance. Nature 2015;527:472-6.

71. Bhatia S, Monkman J, Toh AKL, Nagaraj SH, Thompson EW. Targeting epithelial-mesenchymal plasticity in cancer: clinical and preclinical advances in therapy and monitoring. Biochem J 2017;474:3269-306.

72. Barriere G, Fici P, Gallerani G, Fabbri F, Zoli W, et al. Circulating tumor cells and epithelial, mesenchymal and stemness markers: characterization of cell subpopulations. Ann Transl Med 2014;2:109.

73. Francart ME, Lambert J, Vanwynsberghe AM, Thompson EW, Bourcy M, et al. Epithelial-mesenchymal plasticity and circulating tumor cells: travel companions to metastases. Dev Dyn 2018;247:432-50.

74. Yang J, Weinberg RA. Epithelial-mesenchymal transition: at the crossroads of development and tumor metastasis. Dev Cell 2008;14:818-29.

75. Schmitt D, Andrews J, Tan M. Determination of breast cancer cell migratory ability. Methods Mol Biol 2016;1406:171-80.

76. Pandya P, Orgaz JL, Sanz-Moreno V. Modes of invasion during tumour dissemination. Mol Oncol 2017;11:5-27.

77. Te Boekhorst V, Friedl P. Plasticity of cancer cell invasion-mechanisms and implications for therapy. Adv Cancer Res 2016;132:209-64.

78. Jie XX, Zhang XY, Xu CJ. Epithelial-to-mesenchymal transition, circulating tumor cells and cancer metastasis: Mechanisms and clinical applications. Oncotarget 2017;8:81558-71.

79. Tan EJ, Olsson AK, Moustakas A. Reprogramming during epithelial to mesenchymal transition under the control of TGF $\beta$. Cell Adh Migr 2015;9:233-46.

80. Banyard J, Bielenberg DR. The role of EMT and MET in cancer dissemination. Connect Tissue Res 2015;56:403-13.

81. van Zijl F, Krupitza G, Mikulits W. Initial steps of metastasis: cell invasion and endothelial transmigration. Mutat Res 2011;728:23-34.

82. Lintz M, Muñoz A, Reinhart-King CA. The mechanics of single cell and collective migration of tumor cells. J Biomech Eng 2017;139.

83. Gkretsi V, Stylianopoulos T. Cell Adhesion and matrix stiffness: coordinating cancer cell invasion and metastasis. Front Oncol 2018;8:145.

84. Carlini MJ, De Lorenzo MS, Puricelli L. Cross-talk between tumor cells and the microenvironment at the metastatic niche. Curr Pharm Biotechnol 2011;12:1900-8.

85. Scarpa E, Mayor R. Collective cell migration in development. J Cell Biol 2016;212:143-55.

86. Friedl P, Gilmour D. Collective cell migration in morphogenesis, regeneration and cancer. Nat Rev Mol Cell Biol 2009;10:445-57.

87. Laser-Azogui A, Diamant-Levi T, Israeli S, Roytman Y, Tsarfaty I. Met-induced membrane blebbing leads to amoeboid cell motility and invasion. Oncogene 2014;33:1788-98.

88. Khajah MA, Luqmani YA. Involvement of membrane blebbing in immunological disorders and cancer. Med Princ Pract 2016;25 Suppl 2:18-27.

89. Sabeh F, Shimizu-Hirota R, Weiss SJ. Protease-dependent versus -independent cancer cell invasion programs: three-dimensional amoeboid movement revisited. J Cell Biol 2009;185:11-9.

90. Pinner S, Sahai E. Imaging amoeboid cancer cell motility in vivo. J Microsc 2008;231:441-5.

91. Furge KA, Zhang YW, Vande Woude GF. Met receptor tyrosine kinase: enhanced signaling through adapter proteins. Oncogene 2000;19:5582-9.

92. Paduch R. The role of lymphangiogenesis and angiogenesis in tumor metastasis. Cell Oncol (Dordr) 2016;39:397-410

93. Karlsson MC, Gonzalez SF, Welin J, Fuxe J. Epithelial-mesenchymal transition in cancer metastasis through the lymphatic system. Mol Oncol 2017;11:781-91.

94. Farnsworth RH, Achen MG, Stacker SA. The evolving role of lymphatics in cancer metastasis. Curr Opin Immunol 2018;53:64-73.

95. Karaman S, Detmar M. Mechanisms of lymphatic metastasis. J Clin Invest 2014;124:922-8.

96. Karpanen T, Egeblad M, Karkkainen MJ, Kubo H, Ylä-Herttuala S, et al. Vascular endothelial growth factor C promotes tumor lymphangiogenesis and intralymphatic tumor growth. Cancer Res 2001;61:1786-90.

97. Yazawa Y, Kitahara M. Bilateral endolymphatic hydrops in Menière's disease: review of temporal bone autopsies. Ann Otol Rhinol Laryngol 1990;99:524-8.

98. Vaahtomeri K, Karaman S, Mäkinen T, Alitalo K. Lymphangiogenesis guidance by paracrine and pericellular factors. Genes Dev 2017;31:1615-34.

99. Ji RC. Lymph nodes and cancer metastasis: new perspectives on the role of intranodal lymphatic sinuses. Int J Mol Sci 2016;18.

100. Ran S, Volk L, Hall K, Flister MJ. Lymphangiogenesis and lymphatic metastasis in breast cancer. Pathophysiology 2010;17:229-51.

101. Nakamura Y, Yasuoka H, Tsujimoto M, Imabun S, Nakahara M, et al. Lymph vessel density correlates with nodal status, VEGF-C expression, and prognosis in breast cancer. Breast Cancer Res Treat 2005;91:125-32.

102. Domschke C, Schneeweiss A, Stefanovic S, Wallwiener M, Heil J, et al. Cellular immune responses and immune escape mechanisms in breast cancer: determinants of immunotherapy. Breast Care (Basel) 2016;11:102-7.

103. Terry S, Savagner P, Ortiz-Cuaran S, Mahjoubi L, Saintigny P, et al. New insights into the role of EMT in tumor immune escape. Mol Oncol 2017; $11: 824-46$

104. Wang M, Zhang C, Song Y, Wang Z, Wang Y, et al. Mechanism of immune evasion in breast cancer. Onco Targets Ther 2017;10:1561-73.

105. Francisco LM, Salinas VH, Brown KE, Vanguri VK, Freeman GJ, et al. PD-L1 regulates the development, maintenance, and function of induced regulatory T cells. J Exp Med 2009;206:3015-29.

106. Chen L, Gibbons DL, Goswami S, Cortez MA, Ahn YH, et al. Metastasis is regulated via microRNA-200/ZEB1 axis control of tumour cell PD-L1 expression and intratumoral immunosuppression. Nat Commun 2014;5:5241.

107. Zhang P, Sun Y, Ma L. ZEB1: at the crossroads of epithelial-mesenchymal transition, metastasis and therapy resistance. Cell Cycle 2015;14:481-7. 
108. Chen J, Jiang CC, Jin L, Zhang XD. Regulation of PD-L1: a novel role of pro-survival signalling in cancer. Ann Oncol 2016;27:409-16.

109. Schütz F, Stefanovic S, Mayer L, von Au A, Domschke C, et al. PD-1/PD-L1 pathway in breast cancer. Oncol Res Treat 2017;40:294-7.

110. Sabatier R, Finetti P, Mamessier E, Adelaide J, Chaffanet M, et al. Prognostic and predictive value of PDL1 expression in breast cancer. Oncotarget 2015;6:5449-64.

111. Mazel M, Jacot W, Pantel K, Bartkowiak K, Topart D, et al. Frequent expression of PD-L1 on circulating breast cancer cells. Mol Oncol 2015;9:1773-82

112. Bębenek M, Duś D, Koźlak J. Prognostic value of the Fas/Fas ligand system in breast cancer. Contemp Oncol (Pozn) 2013;17:120-2.

113. Kim R, Emi M, Tanabe K, Uchida Y, Toge T. The role of Fas ligand and transforming growth factor beta in tumor progression: molecular mechanisms of immune privilege via Fas-mediated apoptosis and potential targets for cancer therapy. Cancer 2004;100:2281-91.

114. Paget S. The distribution of secondary growths in cancer of the breast. 1889. Cancer Metastasis Rev 1989;8:98-101.

115. de Groot AE, Roy S, Brown JS, Pienta KJ, Amend SR. Revisiting Seed and Soil: examining the primary tumor and cancer cell foraging in metastasis. Mol Cancer Res 2017;15:361-70.

116. Amelot A, Terrier LM, Mazeron JJ, Valery CA, Cornu P, et al. Timeline metastatic progression: in the wake of the « seed and soil » theory. Med Oncol 2017;34:185.

117. Psaila B, Lyden D. The metastatic niche: adapting the foreign soil. Nat Rev Cancer 2009;9:285-93.

118. Chikina AS, Aleksandrova AIu. The cellular mechanisms and regulation of metastasis formation. Mol Biol (Mosk) 2014;48:195-213.

119. Peinado H, Zhang H, Matei IR, Costa-Silva B, Hoshino A, et al. Pre-metastatic niches: organ-specific homes for metastases. Nat Rev Cancer 2017; 17:302-17.

120. Chin AR, Wang SE. Cancer tills the premetastatic field: mechanistic basis and clinical implications. Clin Cancer Res 2016;22:3725-33.

121. Peinado H, Lavotshkin S, Lyden D. The secreted factors responsible for pre-metastatic niche formation: old sayings and new thoughts. Semin Cancer Biol 2011;21:139-46.

122. Liu ZJ, Semenza GL, Zhang HF. Hypoxia-inducible factor 1 and breast cancer metastasis. J Zhejiang Univ Sci B 2015;16:32-43.

123. Inácio Pinto N, Carnier J, Oyama LM, Otoch JP, Alcântara PS, et al. Cancer as a proinflammatory environment: metastasis and cachexia. Mediators Inflamm 2015;2015:791060.

124. Xie HY, Shao ZM, Li DQ. Tumor microenvironment: driving forces and potential therapeutic targets for breast cancer metastasis. Chin J Cancer 2017;36:36.

125. Cox TR, Rumney RMH, Schoof EM, Perryman L, Høye AM, et al. The hypoxic cancer secretome induces pre-metastatic bone lesions through lysyl oxidase. Nature 2015;522:106-10.

126. Barkan D, Green JE, Chambers AF. Extracellular matrix: a gatekeeper in the transition from dormancy to metastatic growth. Eur J Cancer 2010;46:1181-8

127. Cox TR, Gartland A, Erler JT. Lysyl oxidase, a targetable secreted molecule involved in cancer metastasis. Cancer Res 2016;76:188-92.

128. Erler JT, Bennewith KL, Cox TR, Lang G, Bird D, et al. Hypoxia-induced lysyl oxidase is a critical mediator of bone marrow cell recruitment to form the premetastatic niche. Cancer Cell 2009;15:35-44.

129. Cox TR, Bird D, Baker AM, Barker HE, Ho MW, et al. LOX-mediated collagen crosslinking is responsible for fibrosis-enhanced metastasis. Cancer Res 2013;73:1721-32.

130. Barker HE, Bird D, Lang G, Erler JT. Tumor-secreted LOXL2 activates fibroblasts through FAK signaling. Mol Cancer Res 2013;11:1425-36.

131. Endo M, Nakano M, Kadomatsu T, Fukuhara S, Kuroda H, et al. Tumor cell-derived angiopoietin-like protein ANGPTL2 is a critical driver of metastasis. Cancer Res 2012;72:1784-94.

132. García-Román J, Zentella-Dehesa A. Vascular permeability changes involved in tumor metastasis. Cancer Lett 2013;335:259-69.

133. Saharinen P, Eklund L, Pulkki K, Bono P, Alitalo K. VEGF and angiopoietin signaling in tumor angiogenesis and metastasis. Trends Mol Med 2011;17:347-62.

134. Heymann D, Téllez-Gabriel M. Circulating tumor cells: the importance of single cell analysis. Adv Exp Med Biol 2018;1068:45-58.

135. Desitter I, Guerrouahen BS, Benali-Furet N, Wechsler J, Jänne PA, et al. A new device for rapid isolation by size and characterization of rare circulating tumor cells. Anticancer Res 2011;31:427-41.

136. Li Y, Wu S, Bai F. Molecular characterization of circulating tumor cells-from bench to bedside. Semin Cell Dev Biol 2018;75:88-97.

137. Grover PK, Cummins AG, Price TJ, Roberts-Thomson IC, Hardingham JE. Circulating tumour cells: the evolving concept and the inadequacy of their enrichment by EpCAM-based methodology for basic and clinical cancer research. Ann Oncol 2014;25:1506-16.

138. Lee JS, Magbanua MJM, Park JW. Circulating tumor cells in breast cancer: applications in personalized medicine. Breast Cancer Res Treat 2016;160:411-24.

139. Königsberg R, Obermayr E, Bises G, Pfeiler G, Gneist M, et al. Detection of EpCAM positive and negative circulating tumor cells in metastatic breast cancer patients. Acta Oncol 2011;50:700-10.

140. Campton DE, Ramirez AB, Nordberg JJ, Drovetto N, Clein AC, et al. High-recovery visual identification and single-cell retrieval of circulating tumor cells for genomic analysis using a dual-technology platform integrated with automated immunofluorescence staining. BMC Cancer 2015;15:360.

141. Hillig T, Horn P, Nygaard AB, Haugaard AS, Nejlund S, et al. In vitro detection of circulating tumor cells compared by the CytoTrack and CellSearch methods. Tumour Biol 2015;36:4597-601.

142. Adams DL, Stefansson S, Haudenschild C, Martin SS, Charpentier M, et al. Cytometric characterization of circulating tumor cells captured by microfiltration and their correlation to the CellSearch(®) CTC test. Cytometry A 2015;87:137-44.

143. Vona G, Sabile A, Louha M, Sitruk V, Romana S, et al. Isolation by size of epithelial tumor cells : a new method for the immunomorphological and molecular characterization of circulatingtumor cells. Am J Pathol 2000;156:57-63.

144. Zhou MD, Hao S, Williams AJ, Harouaka RA, Schrand B, et al. Separable bilayer microfiltration device for viable label-free enrichment of circulating tumour cells. Sci Rep 2014;4:7392. 
145. Ozkumur E, Shah AM, Ciciliano JC, Emmink BL, Miyamoto DT, et al. Inertial focusing for tumor antigen-dependent and -independent sorting of rare circulating tumor cells. Sci Transl Med 2013;5:179ra47.

146. Stott SL, Hsu CH, Tsukrov DI, Yu M, Miyamoto DT, et al. Isolation of circulating tumor cells using a microvortex-generating herringbonechip. Proc Natl Acad Sci U S A 2010;107:18392-7.

147. Harb W, Fan A, Tran T, Danila DC, Keys D, et al. Mutational analysis of circulating tumor cells using a novel microfluidic collection device and qPCR assay. Transl Oncol 2013;6:528-38.

148. Kalinsky K, Mayer JA, Xu X, Pham T, Wong KL, et al. Correlation of hormone receptor status between circulating tumor cells, primary tumor, and metastasis in breast cancer patients. Clin Transl Oncol 2015;17:539-46.

149. Xu L, Mao X, Imrali A, Syed F, Mutsvangwa K, et al. Optimization and evaluation of a novel size based circulating tumor cell isolation system. PLoS One 2015;10:e0138032.

150. Sollier E, Go DE, Che J, Gossett DR, O'Byrne S, et al. Size-selective collection of circulating tumor cells using Vortex technology. Lab Chip 2014;14:63-77.

151. Khoo BL, Warkiani ME, Tan DS, Bhagat AA, Irwin D, et al. Clinical validation of an ultra high-throughput spiral microfluidics for the detection and enrichment of viable circulating tumor cells. PLoS One 2014;9:e99409.

152. Gerges N, Rak J, Jabado N. New technologies for the detection of circulating tumour cells. Br Med Bull 2010;94:49-64.

153. Cristofanilli M, Budd GT, Ellis MJ, Stopeck A, Matera J, et al. Circulating tumor cells, disease progression, and survival in metastatic breast cancer. N Engl J Med 2004;351:781-91.

154. Talasaz AH, Powell AA, Huber DE, Berbee JG, Roh KH, et al. Isolating highly enriched populations of circulating epithelial cells and other rare cells from blood using a magnetic sweeper device. Proc Natl Acad Sci U S A 2009;106:3970-5.

155. Chinen LT, de Carvalho FM, Rocha BM, Aguiar CM, Abdallah EA, et al. Cytokeratin-based CTC counting unrelated to clinical follow up. J Thorac Dis 2013;5:593-9.

156. Somlo G, Lau SK, Frankel P, Hsieh HB, Liu X, et al. Multiple biomarker expression on circulating tumor cells in comparison to tumor tissues from primary and metastatic sites in patients with locally advanced/inflammatory, and stage IV breast cancer, using a novel detection technology. Breast Cancer Res Treat 2011;128:155-63.

157. Andreopoulou E, Yang LY, Rangel KM, Reuben JM, Hsu L, et al. Comparison of assay methods for detection of circulating tumor cells in metastatic breast cancer: AdnaGen AdnaTest BreastCancer Select/Detect ${ }^{\mathrm{TM}}$ versus Veridex CellSearch ${ }^{\mathrm{TM}}$ system. Int J Cancer 2012;130:1590-7.

158. López-Riquelme N, Minguela A, Villar-Permuy F, Ciprian D, Castillejo A, et al. Imaging cytometry for counting circulating tumor cells: comparative analysis of the CellSearch vs ImageStream systems. APMIS 2013;121:1139-43.

159. Magbanua MJ, Park JW. Isolation of circulating tumor cells by immunomagnetic enrichment and fluorescence-activated cell sorting (IE/ FACS) for molecular profiling. Methods 2013;64:114-8.

160. Magbanua MJ, Sosa EV, Roy R, Eisenbud LE, Scott JH, et al. Genomic profiling of isolated circulating tumor cells from metastatic breast cancer patients. Cancer Res 2013;73:30-40.

161. Morris RJ. Circulating tumor cells: quintessential precision oncology presenting challenges for biology. NPJ Precis Oncol 2017;1:16.

162. Wallwiener M, Riethdorf S, Hartkopf AD, Modugno C, Nees J, et al. Serial enumeration of circulating tumor cells predicts treatment response and prognosis in metastatic breast cancer: a prospective study in 393 patients. BMC Cancer 2014;14:512.

163. Eisenhauer EA, Therasse P, Bogaerts J, Schwartz LH, Sargent D, et al. New response evaluation criteria in solid tumours: revised RECIST guideline (version 1.1). Eur J Cancer 2009;45:228-47.

164. Raimondi C, Gradilone A, Naso G, Vincenzi B, Petracca A, et al. Epithelial-mesenchymal transition and stemness features in circulating tumor cells from breast cancer patients. Breast Cancer Res Treat 2011;130:449-55.

165. Giordano A, Gao H, Anfossi S, Cohen E, Mego M, et al. Epithelial-mesenchymal transition and stem cell markers in patients with HER2positive metastatic breast cancer. Mol Cancer Ther 2012;11:2526-34.

166. Mego M, De Giorgi U, Dawood S, Wang X, Valero V, et al. Characterization of metastatic breast cancer patients with nondetectable circulating tumor cells. Int J Cancer 2011;129:417-23.

167. Satelli A, Batth I, Brownlee Z, Mitra A, Zhou S, et al. EMT circulating tumor cells detected by cell-surface vimentin are associated with prostate cancer progression. Oncotarget 2017;8:49329-37.

168. Serrano MJ, Ortega FG, Alvarez-Cubero MJ, Nadal R, Sanchez-Rovira P, et al. EMT and EGFR in CTCs cytokeratin negative nonmetastatic breast cancer. Oncotarget 2014;5:7486-97.

169. Duffy MJ, McDermott EW, Crown J. Blood-based biomarkers in breast cancer: From proteins to circulating tumor cells to circulating tumor DNA. Tumour Biol 2018;40:1010428318776169.

170. Austin RG, Huang TJ, Wu M, Armstrong AJ, Zhang T. Clinical utility of non-EpCAM based circulating tumor cell assays. Adv Drug Deliv Rev 2018;125:132-42.

171. Khatami F, Aghayan HR, Sanaei M, Heshmat R, Tavangar SM, et al. The potential of circulating tumor cells in personalized management of breast cancer: a systematic review. Acta Med Iran 2017;55:175-93.

172. Shao Y, Sun X, He Y, Liu C, Liu H. Elevated levels of serum tumor markers CEA and CA15-3 are prognostic parameters for different molecular subtypes of breast cancer. PLoS One 2015;10:e0133830.

173. Gion M, Mione R, Barioli P, Sartorello P, Capitanio G. Tissue polypeptide antigen and tissue polypeptide specific antigen in primary breast cancer. Evaluation in serum and tumour tissue. Eur J Clin Chem Clin Biochem 1994;32:779-87.

174. Tchou J, Lam L, Li YR, Edwards C, Ky B, et al. Monitoring serum HER2 levels in breast cancer patients. Springerplus 2015;4:237.

175. Mokuyasu S, Suzuki Y, Seto T, Miyachi H, Tokuda Y. A comparative clinical evaluation of the assay of serum extracellular domain of HER2 protein using a chemiluminescent immunoassay method in breast cancer patients with or without HER2 protein expression in immunohistochemistry. Rinsho Byori 2012;60:612-20.

176. Fujimoto Y, Higuchi T, Nishimukai A, Miyagawa Y, Kira A, et al. High levels of serum CA15-3 and residual invasive tumor size are 
associated with poor prognosis for breast cancer patients with non-pathological complete response after neoadjuvant chemotherapy. J Surg Oncol 2018; doi: 10.1002/jso.25125.

177. Kucera R, Topolcan O, Fiala O, Kinkorova J, Treska V, et al. The role of TPS and TPA in the diagnostics of distant metastases. Anticancer Res 2016;36:773-7.

178. Tang SS, Gui GP. Biomarkers in the diagnosis of primary and recurrent breast cancer. Biomark Med 2012;6:567-85.

179. Mariani L, Miceli R, Michilin S, Gion M. Serial determination of CEA and CA 15.3 in breast cancer follow-up: an assessment of their diagnostic accuracy for the detection of tumour recurrences. Biomarkers 2009;14:130-6.

180. Smerage JB, Barlow WE, Hortobagyi GN, Winer EP, Leyland-Jones B, et al. Circulating tumor cells and response to chemotherapy in metastatic breast cancer: SWOG S0500. J Clin Oncol 2014;32:3483-9.

181. Larsson AM, Jansson S, Bendahl PO, Levin Tykjaer Jörgensen C, Loman N, et al. Longitudinal enumeration and cluster evaluation of circulating tumor cells improve prognostication for patients with newly diagnosed metastatic breast cancer in a prospective observational trial. Breast Cancer Res 2018;20:48.

182. Lu YJ, Wang P, Wang X, Peng J, Zhu YW, et al. The significant prognostic value of circulating tumor cells in triple-negative breast cancer: a meta-analysis. Oncotarget 2016;7:37361-9.

183. Kang Y, Pantel K. Tumor cell dissemination: emerging biological insights from animal models and cancer patients. Cancer Cell 2013;23:573-81.

184. Van Poznak C, Somerfield MR, Bast RC, Cristofanilli M, Goetz MP, et al. Use of biomarkers to guide decisions on systemic therapy for women with metastatic breast cancer: american society of clinical oncology clinical practice guideline. J Clin Oncol 2015;33:2695-704.

185. Ellsworth RE, Blackburn HL, Shriver CD, Soon-Shiong P, Ellsworth DL. Molecular heterogeneity in breast cancer: State of the science and implications for patient care. Semin Cell Dev Biol 2017;64:65-72.

186. Fehm T, Müller V, Aktas B, Janni W, Schneeweiss A, et al. HER2 status of circulating tumor cells in patients with metastatic breast cancer: a prospective, multicenter trial. Breast Cancer Res Treat 2010;124:403-12.

187. Georgoulias V, Bozionelou V, Agelaki S, Perraki M, Apostolaki S, et al. Trastuzumab decreases the incidence of clinical relapses in patients with early breast cancer presenting chemotherapy-resistant CK-19mRNA-positive circulating tumor cells: results of a randomized phase II study. Ann Oncol 2012;23:1744-50.

188. Paoletti C, Muñiz MC, Thomas DG, Griffith KA, Kidwell KM, et al. Development of circulating tumor cell-endocrine therapy index in patients with hormone receptor-positive breast cancer. Clin Cancer Res 2015;21:2487-98.

189. Arteaga CL, Engelman JA. ERBB receptors: from oncogene discovery to basic science to mechanism-based cancer therapeutics. Cancer Cell 2014;25:282-303.

190. Riethdorf S, Müller V, Zhang L, Rau T, Loibl S, et al. Detection and HER2 expression of circulating tumor cells: prospective monitoring in breast cancer patients treated in the neoadjuvant GeparQuattro trial. Clin Cancer Res 2010;16:2634-45.

191. Bardelli A, Pantel K. Liquid biopsies, what we do not know (yet). Cancer Cell 2017;31:172-9. 